\title{
CARACTERIZAÇÃO DO PROCESSO DE EXPANSÃO URBANA NA BACIA COLÔNIA ANTÔNIO ALEIXO E SUAS CONSEQUÊNCIAS NO DESENVOL VIMENTO DE FEIÇÕES DO TIPO VOÇOROCA, MANAUS-AM
}

\author{
Armando Brito da Frota Filho ${ }^{(\mathrm{a})}$, Antonio Fábio Sabbá Guimarães Vieira ${ }^{(\mathrm{b})}$ \\ (a) Doutorando do Programa de Pós-graduação em Geografia - UFRJ, e-mail: armandofrota.filho@ gmail.com \\ (b) Professor Doutor do departamento de Geografia, Universidade Federal do Amazonas -UFAM, e-mail: \\ fabiovieira@ufam.edu.br
}

Eixo: USO E OCUPAÇÃO DAS TERRAS E LEGISLAÇÃO AMBIENTAL

\begin{abstract}
Resumo
O processo de expansão e crescimento das cidades tem como consequência o desenvolvimento de diversos impactos ambientais, dentre eles destacam-se as feições do tipo voçoroca. O objetivo deste artigo é caracterizar o processo de expansão urbana na bacia Colônia Antônio Aleixo (Manaus-AM) e suas consequências no desenvolvimento de voçorocas. Para tanto foi observado o processo de expansão considerou-se aspectos como traçado da rua e a forma de ocupação, localização da casa em relação à encosta e o direcionamento do sistema de águas servidas e pluviais e o estágio de urbanização. Como resultados, foi possível observar que o impacto da expansão urbana é visível no desenvolvimento das incisões, ao se observar que o elevado número de voçorocas $(\mathrm{n}=22)$ localizadas próximo a vias públicas. Logo apesar das características pedogeomorfologicas apresentam grande influência no desenvolvimento de processos erosivos o fator antrópico é fundamental para seus desencadeamentos e intensificação.
\end{abstract}

Palavras-chave: Erosão; Voçoroca; Bacia Colônia Antônio Aleixo; Manaus.

\section{Introdução}

O ambiente pode ser considerado um sistema resultante das interações de fatores físicos, biológicos, sociais, políticos e culturais que se relacionam no espaço e no tempo (PASSOS, 2009), e tais interações alteram o relevo e paisagem. Á medida que a sociedade transforma a natureza há o aumento na fragilidade ambiental, intensificando as dinâmicas naturais e desencadeando impactos ambientais, tais como os processos erosivos, movimentos de massa, enchentes, dentre outros. Assim, a morfodinâmica representada pelos fatores supracitados superpõe-se à morfoestrutura.

A erosão faz parte do ciclo natural da evolução do modelado do relevo, mas forma geral, os processos erosivos vêm sendo acentuados pela atividade humana através do desflorestamento, retirada das camadas superficiais do solo e de sua compactação, dentre outros. Essas alterações fazem a erosão se tornar mais danosa ao ambiente e impactam cada vez mais ao meio, seja este natural ou social (SUERTEGARAY, 1999; MENDONÇA, 2011). 
No sítio urbano, o desenvolvimento de processos erosivos resulta da combinação de vários fatores, como de âmbito natural tais como: encostas íngremes, características físicas do solo e precipitação elevada. Enquanto no âmbito social e urbano destacam-se o planejamento da cidade, desmatamento, impermeabilização do solo, as formas de ocupações existentes, ou ainda, leis sobre a ocupação de lugares que possam vir a proporcionar o desequilíbrio físico na paisagem devido ao desenvolvimento de erosão.

Na cidade de Manaus-AM, estudos de Vieira (1998), Viera (2008) e Frota Filho (2016) apontam que a geomorfologia local associada a forma de ocupação, em geral sem o devido planejamento, tendem a desenvolver mais feições erosivas lineares e com maior intensidade, gerando voçorocas de grandes proporções e que consequentemente desencadeiam outros impactos ambientais, como no caso da bacia Colônia Antônio Aleixo, que apresenta a maior concentração de incisões erosivas da cidade. Dessa forma, o objetivo deste trabalho é: Caracterizar o processo de expansão urbana na bacia Colônia Antônio Aleixo e suas consequências no desenvolvimento de feições do tipo voçoroca.

\section{2. Área de estudo}

O recorte espacial da área de estudo é composto pela bacia hidrográfica Colônia Antônio Aleixo, localizada na Zona Leste da cidade de Manaus (FIGURA 1). Essa bacia ocupa área de aproximadamente $24,93 \mathrm{~km}^{2}$, composta parcial ou integralmente por 08 (oito) bairros, sendo eles: Distrito Industrial II, Puraquequara, Colônia Antônio Aleixo, Mauzinho, São José do Operário, Tancredo Neves, Jorge Teixeira e Zumbi. 


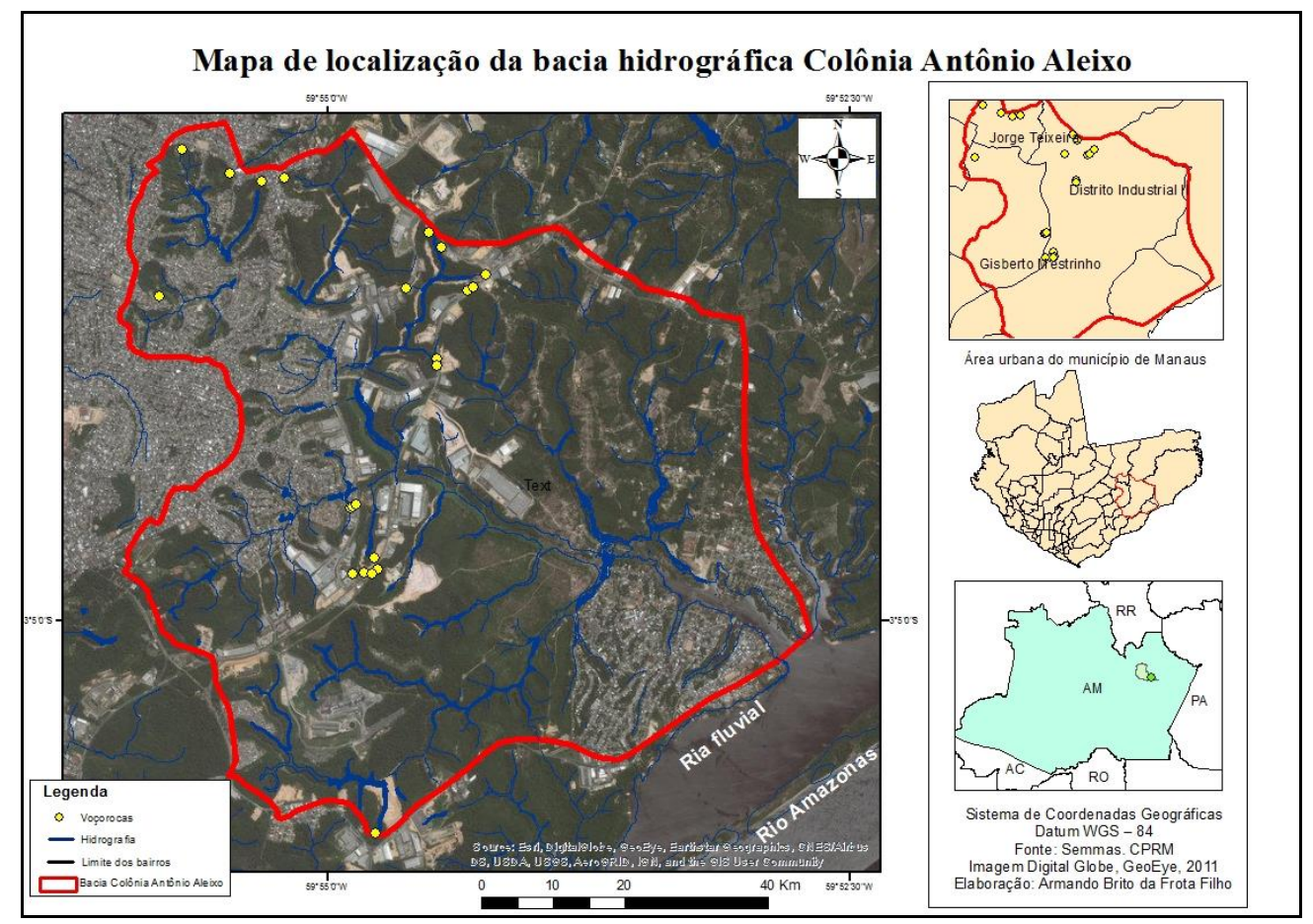

Figura 1: Mapa de localização da área de estudo: Bacia Hidrográfica Colônia Antônio Aleixo.

Fonte: SEMMAS. 2015. Elaboração: Mônica Cortêz Pinto. Org. Armando Brito da Frota Filho

A cidade de Manaus está no contexto geológico-geomorfológico da Unidade Morfoestrutural do

Planalto Dissecado do Rio Trombetas/Rio Negro representado por um sistema de colinas pequenas e médias tabuliformes pertencentes a uma vasta seção de um tabuleiro de sedimentos terciários, variando com cotas entre 50 a 100 metros (SILVA, 2005). Com vales fechados, estreitos e encaixados e zonas de interflúvios estreitas e alongadas (NW-SE e NE-SW) assim apresentando uma intricada e densa rede drenagem (AB'SABER, 1953).

No que se refere aos aspectos pedológicos da cidade, verifica-se em sua maior parte a ocorrência de Latossolos Amarelos localizados nos platôs e na porção superior à média da encosta; e nas porções de média encosta a até próximo aos fundos de vale, encontra-se os Argissolos Amarelos e na parte inferior da encosta e nos baixios, encontram-se os solos ricos em areias, como o Espodossolo (LUCAS, 1989; VIEIRA, 2008).

A vegetação predominante é constituída pelas espécies que compõem a Floresta Ombrófila Densa e o Clima que a sustenta é caracterizado por apresentar uma estação seca de curta duração, o que se enquadra na classificação de Köppen, como Clima A (Clima Tropical Chuvoso) ou mais especificamente Amw. Esse tipo climático para Manaus, apresenta um total acumulado de 2.193,8 mm em média (anual) no, correspondendo ao período de 1917 a 2006 (VIEIRA, 2008), fazendo com que a cidade de Manaus apresente um valor elevado para a taxa de erosividade na ordem de $14.129 \mathrm{~mm} \mathrm{ha}^{-1}$ 
$\mathrm{h}^{-1}$ ano $^{-1}$ (SILVA et al.,2009). A temperatura fica em $26,7^{\circ} \mathrm{C}$, com média das máximas em $31,5^{\circ} \mathrm{C}$ e médias das mínimas em $23,2^{\circ} \mathrm{C}$ (AGUIAR, 1995).

\section{Metodologia}

\subsection{Caracterização do processo de expansão urbana na bacia Colônia Antônio Aleixo e suas consequências no desenvolvimento de feições do tipo voçoroca}

A caracterização do processo de expansão urbana na área de estudo e suas consequências no desenvolvimento voçorocas levou em consideração: 1) classificação do estágio de urbanização; 2) a forma de ocupação e a localização da casa em relação à encosta; 3) a drenagem urbana, e; 4) caracterização da voçoroca.

O estágio de urbanização levou baseou-se em estudos realizados por autores como Tucci e Collischonn (2000), Vieira e Cunha (2009) e Rodrigues e Gouveia (2013), que dividem o processo de urbanização em três fases e seus respectivos impactos ao ambiente.

A forma de ocupação e sua localização na encosta foram realizadas in situ e avaliaram a estrutura e materiais empregados em sua construção, sua posição na encosta (topo, meio ou base) além da proximidade às feições erosivas. No que concerne à drenagem urbana foi observado o saneamento básico (se águas servidas apresentam canalização) e a ausência de bueiros, direcionamento do sistema de águas servidas e pluviais e se são descartadas nas margens das pistas, presença de canaletas, e se as mesmas apresentam dissipadores de energia para que não haja desencadeamento ou aceleração de feições erosivas devido à energia cinética que a água adquiriu ao escoar pela estrutura.
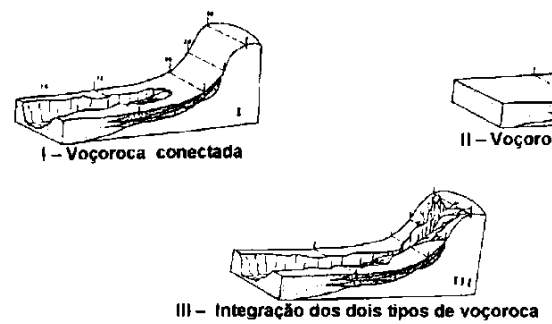

Figura 2: Tipos de voçorocas OLIVEIRA, (1989).
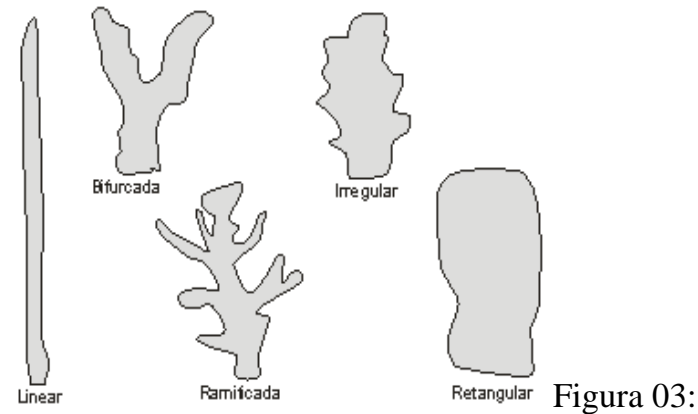

Formas de voçorocas (VIEIRA, 2008)

A caracterização das voçorocas foi realizada com base no cadastro de Vieira (2008) atualizado por Frota Filho (2016) e classificadas quanto ao tipo, através do modelo de Oliveira (1989) (FIGURA 02), quanto à forma pelo modelo de Vieira (2008) (FIGURA 03), além de analises morfométricas das 
incisões. Esses parâmetros serviram de base observar a evolução das voçorocas, seus impactos e o papel da urbanização nesse processo.

\section{Resultados e discussões}

\subsection{Caracterização do processo de expansão urbana na bacia Colônia Antônio Aleixo e suas consequências no desenvolvimento de feições do tipo voçoroca}

A área de estudo é composta por 07 bairros, contudo apenas os três últimos apresentam incisões do tipo voçoroca, em parte, deve-se ao fato destes ocuparem a maior porção da bacia. Entretanto, a forma de ocupação destes bairros colabora para número diferenciado de incisões. Os bairros Gilberto Mestrinho e Jorge Teixeira apresentam 04 incisões cada, enquanto que o Distrito Industrial II apresenta 14 feições.

Essa diferença decorre devido à forma e à fase de ocupação destes bairros, pois as intervenções antrópicas derivadas do processo de urbanização são modificadores do equilíbrio dinâmico natural de vários sistemas (do sistema vertente ao sistema bacia hidrográfica). Quaisquer mudanças na cobertura pedológica implicam em ruptura dos processos originais (RODRIGUES e GOUVEIA, 2013), gerando diversas consequências como o desenvolvimento de feições erosivas, e mesmo, mudanças no regime fluvial.

Autores como Tucci e Collischonn (2000), Vieira e Cunha (2009) e Rodrigues e Gouveia (2013) afirmam que o processo de urbanização apresenta estágios, e cada um deles é responsável por mudanças nas dinâmicas naturais. Para esses autores, o processo de ocupação pode ser dividido em três fases:

a) A primeira fase corresponde à transformação do perímetro pré-urbano para o urbano inicial, na qual ocorre o processo de desmate e retirada da cobertura vegetal, associado à movimentação de grandes volumes de terra e desestruturação das camadas do solo, seguido pela construção de casas, de tanques sépticos e da rede de drenagem de águas servidas e pluviais (VIEIRA e CUNHA, 2009; TUCCI e COLLISCHONN, 2000).

Porém, neste intervalo de tempo, entre o início da urbanização e o loteamento, o solo fica exposto ao desencadeamento de processos erosivos (TUCCI e COLLISCHONN, 2000). Também é nessa fase do processo de urbanização que o escoamento superficial é facilitado, o que ocasiona um aumento da produção de sedimentos e da vazão dos cursos d'água;

b) A segunda fase do processo de urbanização é caracterizada pela urbanização não consolidada e loteamentos em fase ocupação, em que há a produção de formas mais planas por meio da 
instalação e calçamento de ruas e outras edificações, com a execução de cortes e aterros, onde os materiais de menor coesão são erradicados e originam-se descontinuidades morfológicas. Essa fase é caracterizada pela elevação da taxa de escoamento e diminuição da infiltração devido ao aumento considerável de áreas impermeabilizadas, que elevam significativamente a taxa de deposição, como afirmam Tucci e Collischonn (2000) e Rodrigues e Gouveia (2013).

Ainda sobre a segunda fase, Rodrigues e Gouveia (2013) explicitam que é característica a inexistência ou a inadequação da infraestrutura urbana como "pavimentação de ruas, sistemas de microdrenagem, sistema de captação de esgotos ou coleta regular de lixo";

c) A terceira fase trata da consolidação do processo de urbanização, onde ocorrem muitas edificações residenciais e públicas, além da construção de indústrias (VIEIRA e CUNHA, 2009), em que apresenta como consequência o aumento do escoamento, de vazão e das ocorrências de picos de cheia. Conforme Rodrigues e Gouveia (2013), este aumento do escoamento superficial ocorre pelo aumento das superfícies impermeabilizadas associadas à entrada de água no sistema, oriundas de outras bacias para o abastecimento público.

Os bairros Gilberto Mestrinho e Jorge Teixeira exibem uma ocupação consolidada que pode ser considerada como uma transição entre a segunda e a terceira fase de urbanização, enquanto que o bairro Distrito Industrial II, está na segunda fase da urbanização.

Nestes bairros, os aspectos ligados ao saneamento básico e drenagem de águas pluviais e servidas é precário e colaboram no desencadeamento, desenvolvimento e aceleração dos processos erosivos. Fatos estes que explicam o porquê das incisões, em sua totalidade, estarem localizadas próximas às vias urbanas e às residências. Isso ocorre, pois a expansão da malha urbana ocorreu sem o devido planejamento, desconsiderando aspectos naturais e socioeconômicos por tratar-se de "ocupação espontânea" 1 .

No que tange aos aspectos urbanos e sua relação com o desenvolvimento de processos erosivos, a dinâmica dos bairros Gilberto Mestrinho e Jorge Teixeira é semelhante, pois a parte majoritária destes bairros teve "ocupação espontânea", e houve pouca interferência do Poder Público em sua fase inicial. Devido à sua ocupação ser predominantemente residencial e com número expressivo de feições do tipo voçoroca, o Estado interveio por meio da contenção de voçorocas que colocavam em risco residências e aparelhos públicos, na figura 04a e 04b observa-se uma voçoroca em processo de contenção e outra contida.

\footnotetext{
${ }^{1}$ Denominado regionalmente de "invasões"
} 


\begin{tabular}{|c|c|}
\hline $\begin{array}{l}\text { XVII Simpósio Brasileiro } \\
\text { de Geografia Fisica Aplicada }\end{array}$ & $\begin{array}{l}\text { OS DESAFIOS DA GEOGRAFIA FISICA NA FRONTEIRA DO CONHECIMENTO } \\
\text { Instituto de Geociências - Unicamp }\end{array}$ \\
\hline $\begin{array}{l}\text { I Congresso Nacional } \\
\text { de Geografia Física }\end{array}$ & $\begin{array}{l}\text { Campinas - SP } \\
28 \text { de Junho à } 02 \text { de Julho de } 2017\end{array}$ \\
\hline
\end{tabular}

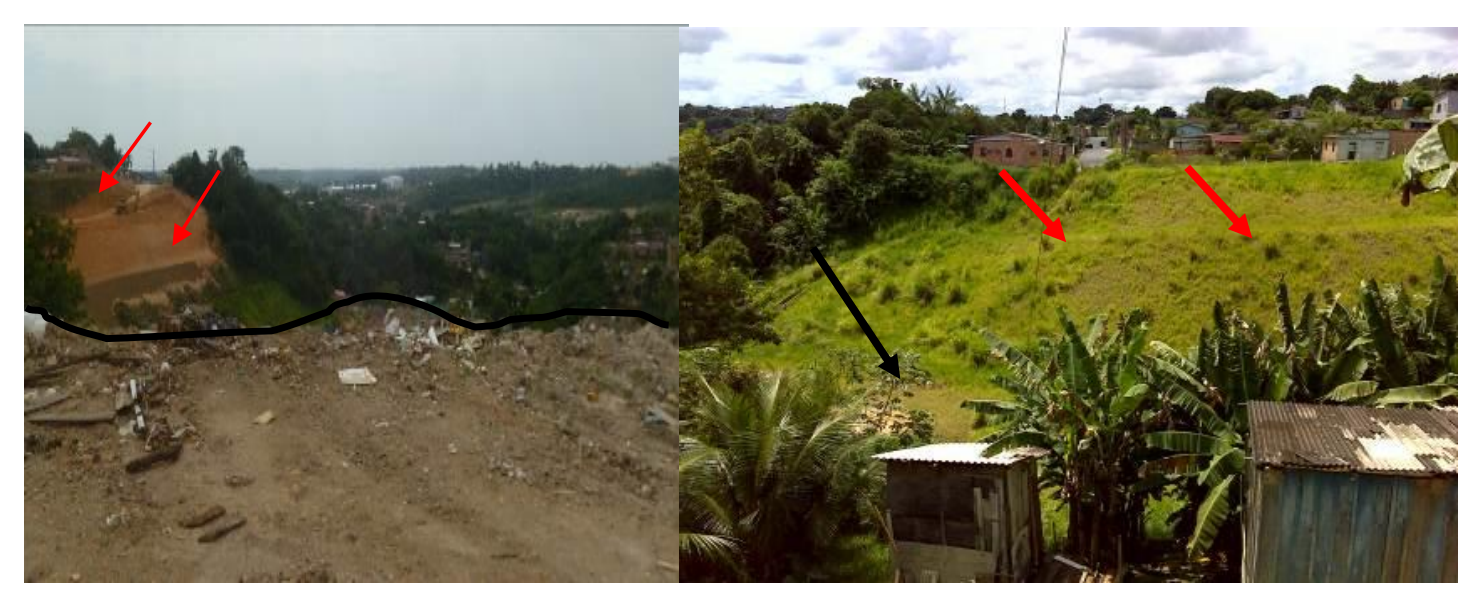

Figura 04: a) Voçoroca em processo de contenção pelo poder público no bairro Jorge Teixeira. A linha preta indica a boda da incisão. As setas vermelhas indicam os patamares. Fonte; Armando Brito da Frota Filho, 2015. b) Voçoroca contida pelo poder público no bairro Jorge Teixeira. As setas vermelhas indicam os patamares. As setas pretas indicam as ocupações em local inapropriado. Fonte: Antonio Fábio Sabbá Guimarães Vieira, 2012.

Na figura $4 \mathrm{~b}$ a população iniciou um processo de ocupação nas bordas da voçoroca e nos patamares, além da plantação de bananeiras, fatores que contribuirão para a reativação desta voçoroca, ou mesmo o desenvolvimento de outras incisões. Ainda sobre a forma de ocupação dos bairros Gilberto Mestrinho e Jorge Teixeira, pode se destacar os fatores que contribuem para o desencadeamento de processos erosivos como: o traçado das ruas, a drenagem urbana (descarte de águas servidas e pluviais).

As ruas dos bairros Gilberto Mestrinho e Jorge Teixeira, devido à própria forma do relevo da região, apresentam tendências a serem mais declivosas que facilitam o escoamento das águas pelas suas laterais, o que ocasiona em aumento de sua energia cinética em face da grande declividade e que podem causar um impacto maior quando atingem a porção inferior da encosta.

Esses bairros também apresentam ruas que terminam nas bordas de voçorocas, como pode ser observado na Figura 05, apesar da rua estar interditada o fluxo de águas servidas vai em direção à incisão, fazendo com que a mesma continue em processo de expansão.

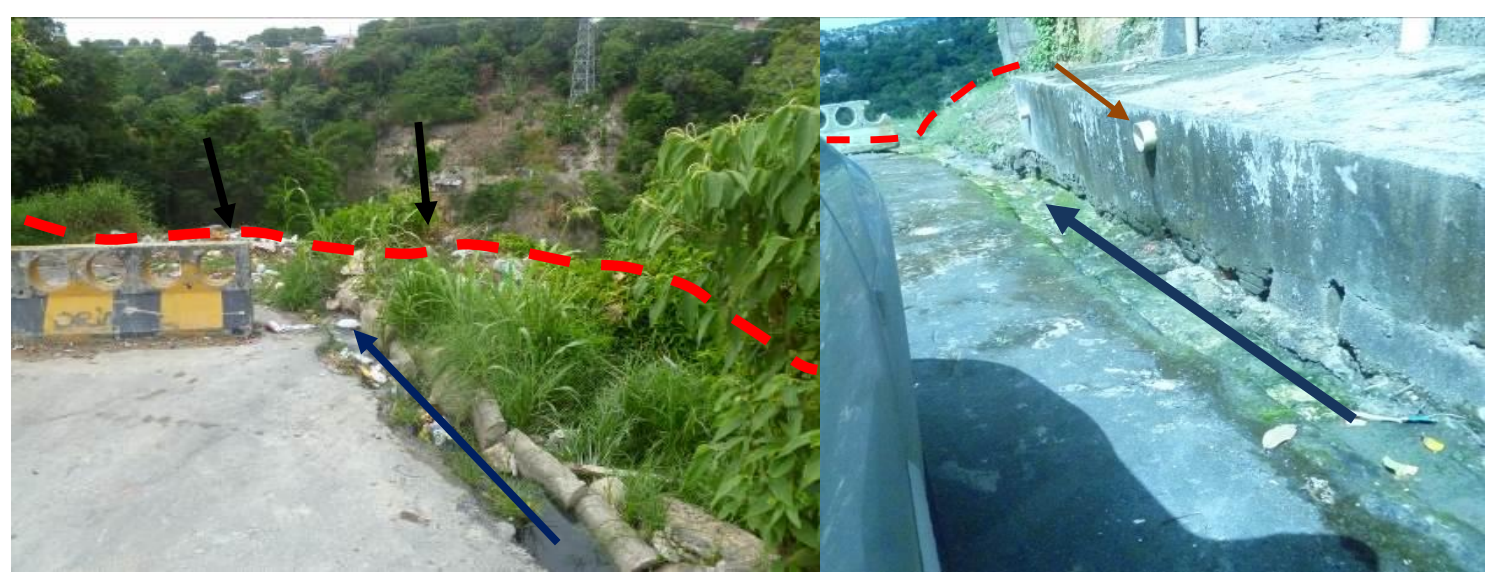


Figura 35: Ruas interditadas próximo as bordas de uma voçorocas no Bairro Jorge Teixeira. Tracejado vermelho indica a borda da incisão. A seta azul indica o sentido do escoamento das águas servidas, setas pretas indicam os resíduos sólidos na borda incisão. Seta marrom indicando o encanamento de águas servidas. Fonte: Armando Brito da Frota Filho, 2015.

Ao seguirem o traçado da rua, as águas pluviais e/ou servidas têm como destino os fundos de vale, e em alguns casos, devido à forma do relevo local combinado aos sistemas de drenagem mal construídos, tendem a desencadear processos erosivos, pois há descontinuidade entre a estrutura de concreto da canaleta e o solo, visto que chegam à meia encosta apenas.

As dinâmicas dos bairros Jorge Teixeira e Gilberto Mestrinho diferem do bairro Distrito Industrial II. Em primeiro lugar devido à forma de ocupação deste último, que em sua maioria, se deu via loteamento do bairro para empreendimentos privados como fábricas, e em uma menor parte, teve "ocupação espontânea".

É possível considerar que o bairro está ainda na segunda fase do processo de urbanização, pois assim como os locais dos referidos empreendimentos ainda estão em fase de implementação, o bairro também apresenta várias áreas com desmatamento e retirada das camadas superficiais do solo, em processo de terraplanagem e aterramento. Ainda ocorre o problema da má estruturação da rede de drenagem urbana, fatores que propiciam o desencadeamento de processos erosivos.

Tais dinâmicas fazendo com que o bairro apresente a maior concentração de voçorocas da bacia $(\mathrm{n}=14)$, além as mesma apresentarem as maiores dimensões (área e volume erodido) e maior impacto aos sistemas pedo-geomorfológico e hídrico da bacia.

Certas dinâmicas como a deposição de resíduos em incisões ganham outra dimensão quando confrontadas com a do bairro Distrito Industrial II, como pode ser observado nas Figuras 06 e 07. Nestas figuras é possível perceber a presença da incisão com a intervenção humana, não no sentido de contê-la, mas de usá-la como local de deposição de rejeitos, onde há a deposição de material Tecnogênico, variando entre Gárbico, Úrbico e, principalmente, Espólicos. 


\begin{tabular}{|c|c|}
\hline $\begin{array}{l}\text { XVII Simpósio Brasileiro } \\
\text { de Geografia Fisica Aplicada }\end{array}$ & $\begin{array}{l}\text { OS DESAFIOS DA GEOGRAFIA FISICA NA FRONTEIRA DO CONHECIMENTO } \\
\text { Instituto de Geociências - Unicamp }\end{array}$ \\
\hline $\begin{array}{l}\text { I Congresso Nacional } \\
\text { de Geografia Física }\end{array}$ & $\begin{array}{l}\text { Campinas - SP } \\
28 \text { de Junho à } 02 \text { de Julho de } 2017\end{array}$ \\
\hline
\end{tabular}
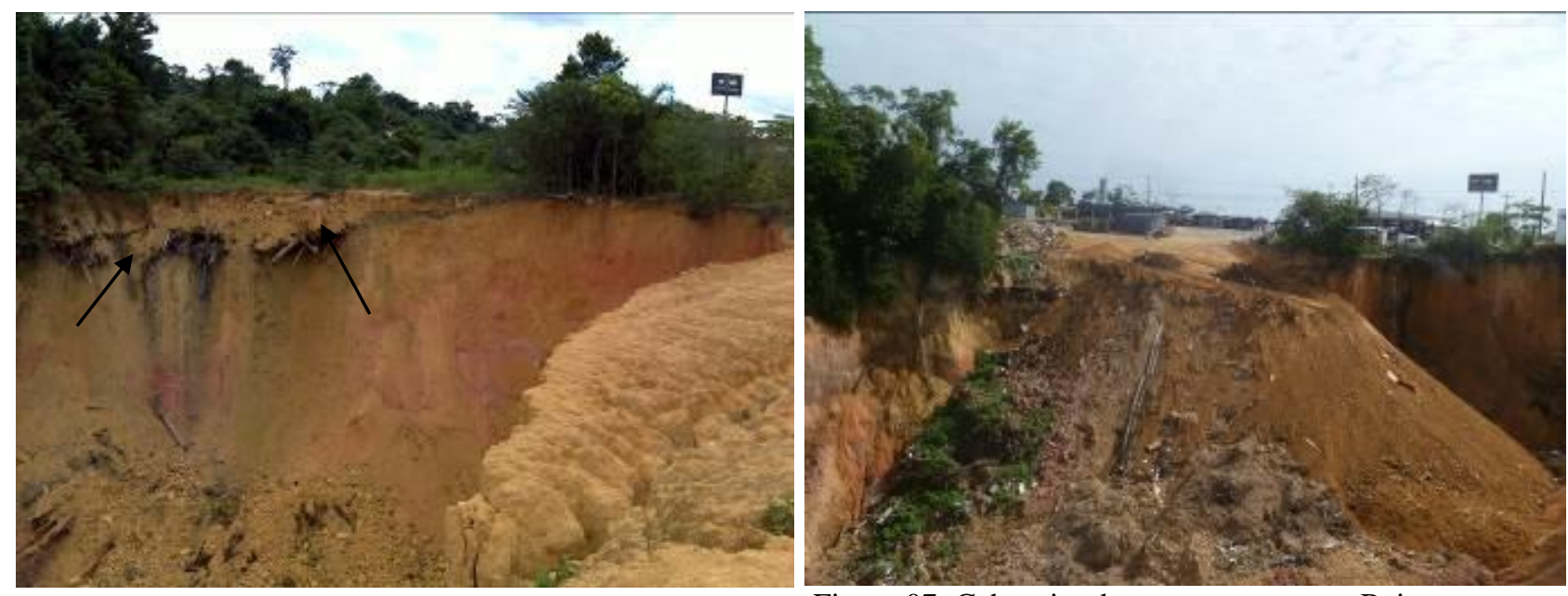

Figura 06: Cabeceira de uma voçoroca no Bairro

Figura 07: Cabeceira de uma voçoroca no Bairro Distrito Industrial II, com intervenção humana e deposição tecnogênica.Fonte: Armando Brito da Distrito Industrial II.Setas pretas indicam os restos de uma árvore. Frota Filho, 2015

Fonte: Antonio Fábio Sabbá Guimarães Vieira, 2011.

Dentre os maiores impactos decorrentes da ocupação não planejada está o assoreamento de canais fluviais, como pode ser observado na figura 08 , onde o canal a jusante da incisão recebe os sedimentos carreados. A voçoroca abaixo apresentou e no ano de 2015, volume erodido de $281623 \mathrm{~m}^{3}$, essa quantidade de material carreada à rede de drenagem, ocasionou a alteração da composição da paisagem e o regime hidrológico da bacia.

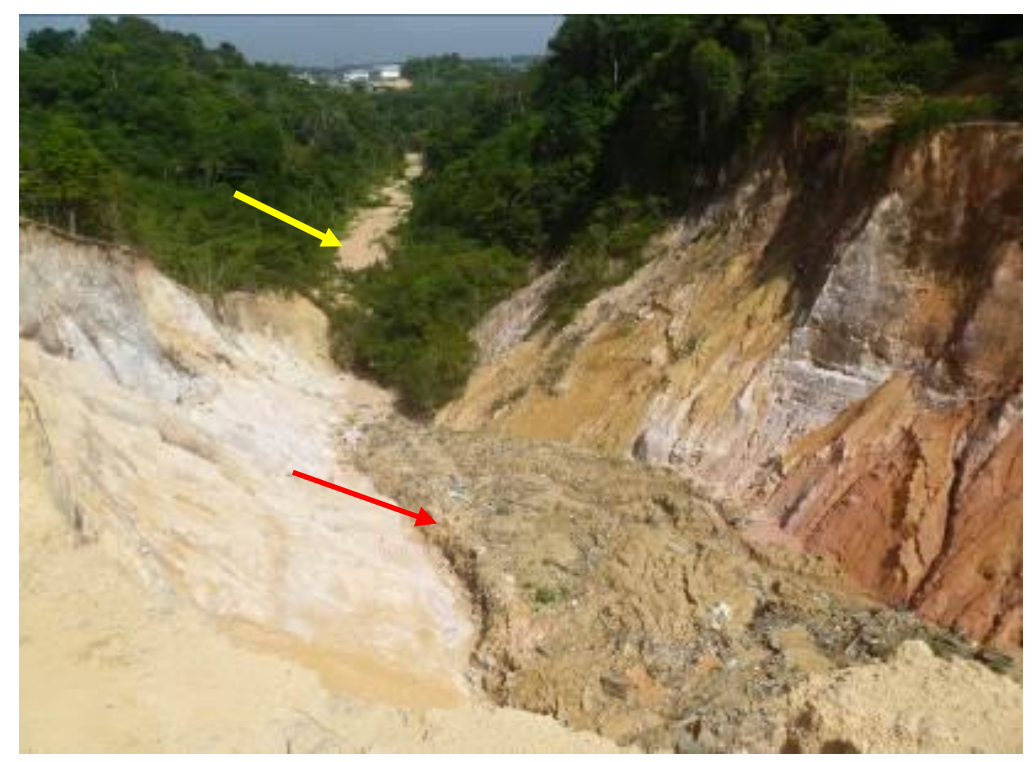

Figura 08: Interior de uma voçoroca no Bairro Distrito Industrial II, com intervenção humana e deposição tecnogênica. Seta Vermelha indica a localização da Deposição Tecnogênica; Seta amarela indica o canal assoreado. Fonte: Armando Brito da Frota Filho, 2015. 
Outro ponto importante é a presença de deposição de outros materiais (deposição tecnogênica) no interior da incisão, fazendo com que o volume carreado seja ainda maior, causando outros impactos como a contaminação de cursos hídricos e de lençóis freáticos.

\section{Conclusão}

A geomorfologia e a pedologia têm papeis primordiais no desenvolvimento de qualquer processo erosivo seja ele natural ou intensificado pela ação humana, contudo a forma que a sociedade interfere no ambiente natural é um fator decisivo no desenvolvimento das incisões, com relação quantidade e suas dimensões.

A fase/estágio de urbanização de uma região tem grande influencia no desenvolvimento e aceleração no processo erosivo, no caso da bacia Colônia Antônio Aleixo, locais como o caso do bairro Distrito Industrial II, que apresenta um impacto maior e mais intenso no ambiente, possui a maior concentração de incisões, visto que por estar na segunda fase da urbanização apresenta muitas áreas recém-desmatadas e com solo exposto, além falta de drenagem de águas (pluviais e servidas).

Quando em contraste com locais que estão em fases mais avançadas como os bairros Gilberto Mestrinho e Jorge Teixeira, ambos em transição da fase dois para fase três observasse uma diminuição na quantidade e na proporção das voçorocas, em especial devido a consolidação urbana e intervenção do Poder Público.

Considerando que não foram encontradas voçorocas em áreas vegetadas, somente me regiões limítrofes ou próximas, pode se inferir que a principal causa das voçorocas na área é a intervenção humana, e mesmo as incisões encontradas em áreas com de contato (meio urbano/meio natural) somente desenvolveram-se devido a presença de canaletas sem dissipadores de energia. Isto posto, mostra o retrato da forma de ocupação (urbana ou rural) na atualidade e a ineficácia do poder público, para fiscalizar e mesmo impedir a ocupação de áreas vulneráveis sejam ocupadas, seja na cidade de Manaus, como no resto do Brasil.

\section{Bibliografia}

AB'SABER, A.N. A cidade de Manaus (primeiros estudos). Boletim Paulista de Geografia, São Paulo, v. 15: p.18-45. 1953.

AGUIAR, F. E. O. As alterações climáticas em Manaus no século XX. Dissertação (Mestrado) Universidade Federal do Rio de Janeiro - UFRJ: Instituto de Geociências: Departamento de Geografia. Rio de Janeiro. 182 p. 1995. 
FROTA FILHO, A.B. Análise da vulnerabilidade erosiva da Bacia Hidrográfica Colônia Antônio Aleixo, Manaus-AM. (Dissertação de Mestrado). Manaus-AM: ICHL/UFAM. 196 p. 2016

LUCAS, Y. System pedologiques en amazonie bresilienne equilibres, desequilibres et transformation. (Tese de Doutorado) Paris - França, L'Université de Poitiers - U.F.R. SCIENCES FONDAMENTALES ET APPLIQUEES, 184 p. 1988

MENDONÇA, F.A. Geografia Física: Ciência Humana?. 8. ed. São Paulo. Sp.: Contexto, 2011. v. 1. 89p.

OLIVEIRA, M.A.T. de. Erosion Disconformities and Gully Morphology: A Threedimensional Approach. In: Catena: an interdisciplinary journal of Soil Science Hydrology - Geomorphology. Vol. 16. W. Germany: Catena Verlag. p. 413- 423. 1989.

PASSOS, M. M. O GTP: Geossistema - Território - Paisagem. Um novo paradigma?. In: 12 EGAL, 2009, Montevideu/Uruguai. Caminando en una América Latina en transformación. Montevideu/Uruguai: Easy Planters, 2009. v. 1. p. 246-272

RODRIGUES, C.; GOUVEIA, I. C. M-C. A Importância Do Fator Antrópico Na Redefinição De Processos Geomorfológicos E Riscos Associados Em Áreas Urbanizadas Do Meio Tropical Úmido. Exemplos Na Grande São Paulo.. In: Antonio José Teixeira Guerra;Maria do Carmo Oliveira Jorge. (Org.). Processos Erosivos e Recuperação de Áreas Degradadas. 1ªed.São Paulo: Oficina de Textos, 2013, v. , p. 01-192.

SILVA, A. M.; SILVA, M. L. N. ; CURI, N. ; AVANZI, J. C. ; FERREIRA, M. M. . Erosividade da chuva e erodibilidade de Cambissolo e Latossolo na região de Lavras, Sul de Minas Gerais. Revista Brasileira de Ciência do Solo (Impresso), v. 33, p. 1811- 1820, 2009

SILVA, C. L.; Análise da tectônica cenozoica da região de Manaus e adjacências. (Tese de Doutorado). Rio Claro - SP.: UNESP, 309p. 2005.

SILVA, A. M. Rainfall erosivity map for Brazil. Catena, v.57. p, 251-259. 2004

SUERTEGARAY, D.M.A. Notas sobre epistemologia da Geografia. In: Cadernos Geográficos / Universidade Federal de Santa Catarina. Centro de Filosofia e Ciências Humanas. Departamento de Geociências. N.1 (Maio 1999)-. - Florianópolis: Imprensa Universitária, 1999

TUCCI, C.E.M; COLLISCHONN, W. Drenagem Urbana. In: TUCCI, C.E.M.; BERTO NI, J.C. (Org.). Inundações urbanas na América do Sul. Porto Alegre: Associação Brasileira de Recursos Hídricos, 2003.p. 45141.

VIEIRA, .A.F.G. (1998). Erosão por voçorocas em áreas urbanas: o caso de Manaus (AM). (Dissertação de Mestrado). Florianópolis: DPGG/UFSC. 181 p.

VIEIRA, A.F.G. Desenvolvimento e distribuição de voçorocas em Manaus (AM): principais fatores controladores e impactos urbano-ambientais. (Tese de doutorado). Florianópolis: UFSC/CFH, 2008. 